\title{
United Technologies Corporation Moves to Virtual Information Services
}

Noreen Steele

Follow this and additional works at: https://jdc.jefferson.edu/scitechnews

\section{Let us know how access to this document benefits you}

\section{Recommended Citation}

Steele, Noreen (1998) "United Technologies Corporation Moves to Virtual Information Services," Sci-Tech News: Vol. 52 : Iss. 4 , Article 3.

Available at: https://jdc.jefferson.edu/scitechnews/vol52/iss4/3

This Article is brought to you for free and open access by the Jefferson Digital Commons. The Jefferson Digital Commons is a service of Thomas Jefferson University's Center for Teaching and Learning (CTL). The Commons is a showcase for Jefferson books and journals, peer-reviewed scholarly publications, unique historical collections from the University archives, and teaching tools. The Jefferson Digital Commons allows researchers and interested readers anywhere in the world to learn about and keep up to date with Jefferson scholarship. This article has been accepted for inclusion in Sci-Tech News by an authorized administrator of the Jefferson Digital Commons. For more information, please contact: JeffersonDigitalCommons@jefferson.edu. 


\title{
UNITED TECHNOLOGIES CORPORATION MOVES TO VIRTUAL INFORMATION SERVICES
}

\author{
By Noreen Steele
}

\author{
"I have some suggestions on how we can do better. The first is a relentless \\ dissatisfaction with our current situations. Regardless of how well we \\ perform today, we can always do better." \\ -- George David, CEO, United Technologies Corporation
}

United Technologies (UTC) is a global corporation of 180,000 employees, of which 105,000 are located outside the United States. UTC manufactures products for the aerospace, building and automotive industries. Major business units include Carrier, Hamilton Standard, Otis Elevator, Pratt \& Whitney, Sikorsky Aircraft and UT Automotive. United Technologies Research Center, located in East Hartford, Connecticut, is the research and development center for the entire corporation. It is the headquarters for the UTC Information Network (UTC IN), formerly called UTLIS (United Technologies Library \& Information Services). Our services are available to all UTC employees. We currently provide information products and services to 16,000 employees worldwide.

Since 1993 UTC IN has maintained a virtual library in Tokyo, Japan, that is, a library with no collections. This site is responsible for providing information products and services to UTC employees in the Pacific Rim. It also provides other UTC employees with information available only in Japan or in the Japanese language.

Until 1996 UTLIS was a centralized library network of 11 mini-libraries located around the corporation. Our management, centralized purchasing, processing, inter-library loan and desktop technology were located at the Research Center. Our major products and services were literature searching, customized current awareness, general current awareness publications, desktop access to several external and internal databases and facilitation of technology between the UTC business units. Our printed collection was approximately 500,000 volumes.

\section{Business Forces}

Although we have numerous examples of our positive impact on both our customers and UTC, in the spring of 1996 there were subtle signs that we were not so effective as we might have been. The number of registered customers had stabilized at 15,000. As more employees heard about our services, we should have seen substantial increases in this number.

Some of our customers were asking for new services. Instead of lacking information, they cited data overload as a major problem. They had difficulty making decisions and advancing projects because they had to wade through too much data.

For several years, we had provided desktop access to several external databases, such as Compendex, ISI Current Contents and ABI Inform, and to internal resources including a database of internal experts, indices, internal technical reports and corporate-wide benchmarking reports. Hardware and software incompatibility problems prohibited most of our customers from connecting to our system. When they could connect, it was difficult to use.

Other customers knew there was a lot of valuable knowledge within the company that they would like to take advantage of, but they didn't have the skills to capture or use it.

There were also signs of change outside UTC. Independent information brokers were actively pursuing UTC's technicaland business staff, promising them better information services and faster turnaround time, all for less money. Head-to-head presentations showed our customers that we had the competitive edge, but for how long?

For several years, even as the costs of printed materials kept rising, we maintained our 
services with no budget increase. To control the skyrocketing costs for journal subscriptions, we monitored the number of photocopies we made for each title. We discovered that we were subscribing to many expensive journals that were used only a few times a year. In one case, only four articles were requested from one journal that cost nearly $\$ 6,000$. We could have purchased all four articles from a document supplier for approximately $\$ 60$.

Purchasing multiple copies and "just in case" titles was no longer an option for us. Suddenly, also, electronic publishing became a reality. Publishers such as the Institute of Physics and Elsevier offered full image, electronic versions of their journals on the Internet.

We spent a lot of time benchmarking our services with other large corporate libraries. We discovered some were offering services that we were not. Some provided analyzed reports and current awareness updates. Others facilitated the capture and use of their company's intellectual capital. Many offered desktop access to a variety of internal and external resources via the Web.

We decided to offer all these products plus a few others. In order to do so without increasing our budget, we had to change the way we were structured, the way we offered services and the allocation of our funds. In early May 1996 we developed a new model to provide more value-added services, accessible to UTC's employees around the world, at a more cost effective price.

\section{UTC Information Network}

Under our new design we became more proactive. Instead of providing only good literature searching, we began offering the option to summarize, filter and analyze information. Instead of just sitting in the library, surrounded by good resources, waiting for customers to come to us, we moved to where the customers were located. There we could anticipate their information needs before they did. Instead of serving just the customers located within close proximity of the mini-libraries, we increased access to information for all UTC employees worldwide.

Although we had some examples of our involvement in internal technology transfer, such as two internal report databases, an internal expert database and databases on UTC benchmarking projects, we decided to further facilitate the capture and sharing of the company's intellectual property. Although we are reducing our collection to core materials, we will not reduce our clients' access to the information they require. On the contrary, we will increase it by partnering with one or two vendors to provide access to 'just-in-time' resources from around the world. As more and more information is available on the Internet, we are replacing subscriptions for printed materials with ones for electronic materials.

\section{Research Analysts}

A Research Analyst Service is now being offered to specific groups or departments such as technical project groups and strategic planning. Our research analysts interact with business analysts or technical professionals to write reports that not only summarize and filter information, but also point out trends and make recommendations. Research analysts are also participating members of their groups, attending meetings and providing proactive on-the-spot information. As part of our knowledge facilitation initiatives, research analysts work with team members to help them determine which of their team-generated information should be captured and used.

Currently we have research analysts in five locations: corporate headquarters, the Research Center, Pratt \& Whitney and in Tokyo, Japan and Aachen, Germany. Our analysts have become involved with important and complex projects much more quickly than anyone anticipated. They are making recommendations on possible acquisitions, providing detailed statistics for our CEO and writing weekly annotated updates on a variety of business interests.

By mid-1998 we plan to add another two positions, all in the business areas. We are working on setting up a similar service for our technical areas, where analysts would probably be associated with multiple short-term projects. Finding and training qualified staff becomes a problem as the demand for this service grows. The logistics of a technical research analyst "floater" with specific technical subject expertise may limit our movement into this area.

\section{Information Managers}

We have closed all 10 traditional libraries, centralizing their collections at the Research Center and locating the reference librarians in offices closer to their customers. The offices have state-of-the-art workstations and a small bookcase of core printed 
reference materials. Renamed information managers, the reference librarians continue to provide 'one-stop shopping' for information. In addition to all the traditional services, they provide proactive information. Although we've always prided ourselves on being proactive, what we really meant was "we're ready when you are." When someone contacted us with a request for information, we were ready with the materials and expertise to answer it. Under the new model, our information managers sit on cross-functional teams as participating members. Equipped with laptop computers with access to the Internet and approximately 6,000 commercial databases, they anticipate information needs and offer help on the spot. Information managers also work with teams to facilitate knowledge management.

UTC IN has 12 information managers in seven business units. Each is located in an office setting. The perception of our services and the expectations of what we can do have risen sharply since we reorganized. We are more in touch with our customers. We are able to take advantage of unexpected opportunities such as acting as consultants to departments that are struggling with information flow.

In the coming months information managers hope to become more involved with knowledge management, particularly performing information audits and training employees to know what, how and why to capture and use internal information.

The biggest problem for this group is their isolation from other members of UTC IN. To help remedy this situation, we have increased the number of times the staff gets together for meetings and added a 'water cooler' session. They can use this time to interact with each other, in a casual setting, on whatever topic comes to mind.

\section{Knowledge Facilitation}

From a central location, knowledge facilitators provide reference services to UTC employees around the world, supply the supporting documentation, and coordinate and integrate desktop access to internal and external resources via the Web.

The INET team, responsible for all Internet and Intranet resources, functions as a self-directed team. It is their job to obtain, codify and provide access to quality external resources and pertinent internal information. The INET team implements and maintains a search engine on the IN homepage which will provide links to Intranets around the corporation. They provide customers with the tools to search internal and external sources at the same time. They will have the ongoing responsibility of assessing and implementing new technologies such as intelligent agents and JAVA applications.

Currently we've added several individual full image electronic journals, both paid subscriptions and appropriate free ones. Others are available as full image or full text articles on services such as UMI's ProQuest Direct.

During the past year we've also added new comprehensive seryices, tested others and provided Web access to many of our internal databases. In addition to ProQuest Direct, we have added ISI's Current Contents, EI Village and SRI Business Intelligence Reports. After completing a pilot, we decided against subscribing to a permanent news feed service, because the costs were too high.

Someday we hope our customers will be able to link from one full image article to another electronic browsing. Once the technology is in place, we will offer current awareness alerts on internal information as well as external. In fact, searching external and internal files will become transparent to the user.

Unfortunately, it is often easier to imagine the future than it is to make it a reality. The costs are prohibitive in many cases. Unless vendors are willing to offer global licenses and formulas which do not count every employee as a user, large companies like ours, will not be able to afford their products. At a recent staff meeting, we spent a lot of time deciding which products were essential and which were just nice to have. Most of the 'nice to have' were eliminated, because our budget can stretch only so far.

However, in 1998 we will add new desktop products. We'll provide access to full image patents, a new Web-based database of internal experts and a database of full text internal technical reports.

Accessible via a toll-free number, internal UTC numbers, e-mail and fax, our Global Information Support group answers general reference questions from both customers and staff. Initially, this provides customers extended hours, from 6 a.m. to 7 p.m. Eventually, by taking advantage of our locations here, in Tokyo and in Aachen, Germany, we hope to be able to provide 24-hour reference service. 
To ensure that this group continues to develop and keeps abreast of the latest reference techniques, we plan to offer internships to students from the top information schools. These interns will oversee special projects such as electronic vertical files and work with the group to provide general reference.

Our Printed Resources group is responsible for providing all printed materials either from our own collection or from external sources around the world. Although working on a much smaller scale than formerly, they will continue to develop and maintain a core collection of books, reports and journals. They will work closely with vendor partnerships providing 'just in time' documents.

Our biggest issue concerning this group is size. Currently, seven people are overseeing a book collection approximately half its original size and a journal collection consisting of about the same number of current subscriptions. In the future, we expect that most journals will become available electronically and fewer books will be purchased. We may decide to outsource various functions such as cataloging, ILL or photocopying. How do we provide enough staff today to ensure speedy turnaround while facing a need for a smaller team in the long term?

\section{Lessons Learned}

How did our customers react to the announced changes? How did we sell the idea? How did other departments like IT accept the move away from the perceived role for libraries? This was a major change for the staff. Did they buy-in? Did the roll-out of UTC IN affect our relationships with our vendors? Would we begin working with all new vendors or differently with old ones?

How did we make the transition from our traditional library system to this new model? The transition is like a complicated logic puzzle, moving one step at a time. Was it easy? Did we learn any lessons along the way?

\section{Customers}

Most of our customers were too distant or too busy to visit any of our libraries. For this majority, the reorganization had no negative effect. But for the 200 - 300 users who did come into the libraries, the changes were unwelcome. Most admitted missing the printed newspapers, the freedom to browse the printed materials and a quiet place to work. At first they had difficulty seeing any advantages to our new model. Slowly, most have begun to realize they have faster access to more information and have reluctantly accepted the changes.

\section{Marketing Campaign}

To make sure our customers understood what our new services would do for them, we developed a corporate-wide marketing campaign. The campaign was rolled out in January 1997, including a new name and a new logo. To 'kick off' the campaign, we sent a letter to every registered user. By now that totaled nearly 16,000. The campaign used a toolbox theme - UTC IN services are your tools for finding, assimilating and using information for a competitive edge.

The big bright red toolbox has three shelves which depict the three types of IN services: desktop access, global information support and on-site research and analysis. The box is filled with gold foil wrapped chocolate candy. Each piece is stamped with either the IN logo or an icon from the UTC IN homepage. When members of the IN staff visit customers or make presentations, they use the toolbox to describe the IN services. The theme is continued in a special slide presentation, in signs in the information managers' offices and as the design for a small brochure.

The marketing campaign also included a redesigned homepage that incorporates our new name and logo. We made sure that our homepage was linked to every business unit's homepage. A CD-ROM brochure, that is an interactive description of all of our services and how other satisfied customers have used them, completed the initial advertising campaign.

All the new information managers traversed their business units, making numerous presentations to a variety of potential customers. The results have been incredible. Demand for these new services is beyond our wildest dreams. The downside is trying to keep up with this demand.

\section{The Staff}

After I presented the model to the staff at a special meeting in late June 1996, several were visibly upset because of the uncertainty of their jobs. It was not until the entire staff attended a two-day seminar on change management that almost everyone was able to support wholeheartedly the new initiatives. This seminar was the point when the staff as a whole bought into the model. 
Helping the staff upgrade their skills for the new positions within IN or preparing them for positions outside the department has been a primary consideration since the new model's conception. We hired a career counseling consultant and purchased a state-of-the-art interactive computer-based skills assessment tool. Most of the staff received four hours of individual counseling time during 1997. Additional time was made available for those who needed it.

Because the three Knowledge Facilitator groups were not accustomed to working together, the career counselor helped them understand the individual personalities that make up the group and taught them teaming fundamentals. This training enabled them to work well together and to begin to develop as a team.

\section{Vendors}

As vendors develop new products or hear about our initiatives, they are extremely eager to partner with us. Some of the vendors have provided us with new and exciting products. We have made several new Web-based information sources accessible on our homepage. Many of the products formerly available only in print or on CD-ROM are among them. We have subscribed to the electronic full-image journals, current awareness services and news feeds.

\section{Results}

The results of these new initiatives will put us in alignment with our customers' information needs. By getting out of the library, co-locating with our customers and attending their meetings, we are not only more accessible to them, but we know the direction they are going and are able to anticipate their needs .

These initiatives enable us to provide more cost effective service. Although our budget remains the same, we have greatly increased the value for users.

Instead of putting information where very few can retrieve it, we have mainstreamed our desktop access where everyone is -- the Web. UTC IN is more visible, a lot more! We're everywhere, on project teams, at the water cooler, at senior level meetings and part of strategic planning groups.

\section{What's Ahead}

We are now completing our 18-month transition process. We've completed almost every initiative within the timeframe allotted. It has helped that the model has been enthusiastically received by most of our customers. Many have suggestions for improving and expanding it.

Many groups around the corporation have expressed a desire to partner with us in areas of Web technology, knowledge management facilitation and linguistics. Our vendors are also interested in what we're doing and are eager to work with us to develop new products, services and software.

We have formed a New Opportunities team that has the responsibility of enhancing this vision and creating new visions. They will be responsible for making sure our services are aligned with our corporation's goals. Individual staff members will be able to help by finding out what's going on in the information industry and in the industries of our corporation. All staff members are encouraged to attend at least one information industry conference and one related to one of our company's industries each year.

Both our external vendors and our internal partners are giving us additional opportunities for change. We have been asked to work with vendors to beta test new products and to provide input into the design and implementation of several additional products and services. We are currently partnering with one company to design computer-aided translation software. Other projects include pilots of Internet news feeds and many current awareness products.

We are trying to take advantage of additional change. We have had the unexpected opportunity to work with some internal departments on information flow within their groups. We have also acted as consultants to groups trying to set up knowledge management structures and as links to various groups who are working on similar projects.

Although we think we're on the right track with our new services and products, we keep reminding ourselves of something Will Rogers once said, "Even if you are on the right track, you'll still get run over if you just sit there."

\footnotetext{
Noreen Steele was manager of the UTC Information Network (UTC IN) at United Technologies when this article was written. She has since started her own consulting business, Information Initiatives, LLC. She can be reached at Information Initiatives, 156 Pine Street,
} 
Columbia, CT 06237 ; by phone at $860 / 228-9454$; by fax at (860/228-0171, or by e-mail at noreen.o.steele@snet.net.

This article has been reprinted in its entirety from Bulletin of the American Society for Information Science, volume 24 no. 6, August/September, 1998, with permission of the American Society for Information Science, Silver Spring, MD.

\section{Used Books Purchased}

Physics, Scholarly Mathematics, Chemistry, Engineering, Electronics, Construction, Skilled Trades

Older Editions, Duplicates, Unneeded Gifts, Superseded Titles

Powell's Technical Bookstore is always seeking quality material in the above areas. If you're tired of throwing good books away or the hassle and meager returns from public book sales, we may have some attractive alternatives for you. For more information please contact

Collier Brown or Kirsten Berg at:

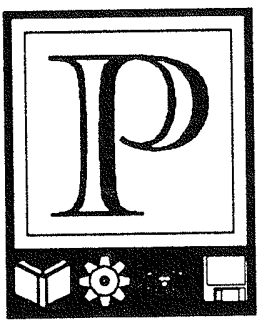

Powell's Technical Bookstore

33 NW Park - Portland, Oregon • 97209

(503) 228-3906 - Fax (503) 228-0505

Toll Free (US \& Canada) • (800) 225-6911

Email: kirsten@technical.powells.com

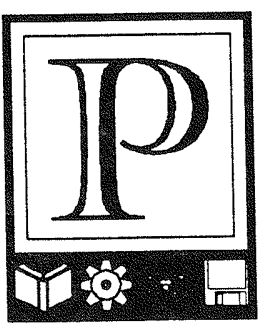




\section{The definitive reference on industrial robotics- now in an up-to-date new edition}

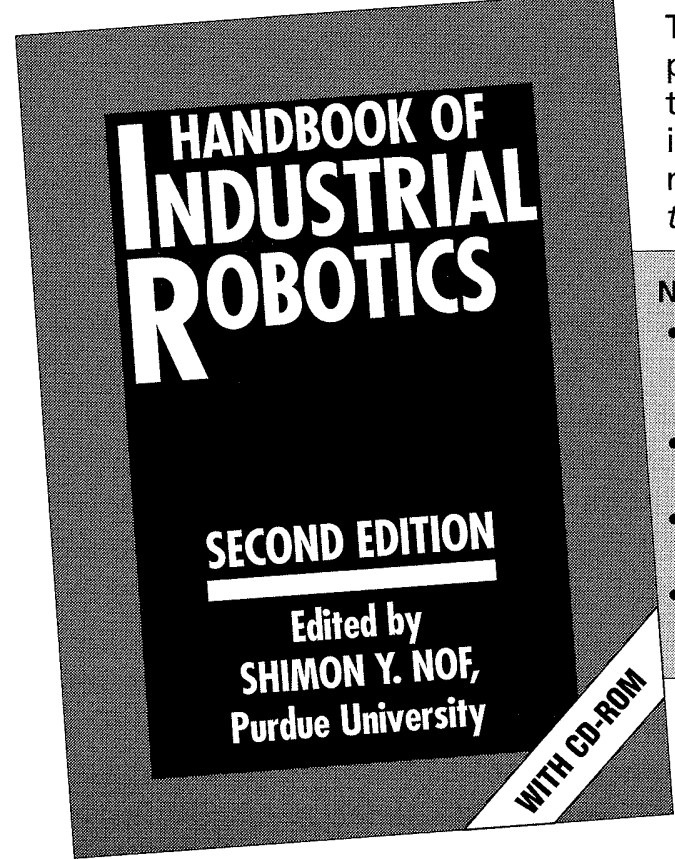

The brand new Second Edition of this bestselling reference provides comprehensive one-stop coverage of both state-ofthe-art research and applications in the burgeoning field of industrial robotics. With contributions from the most prominent names in robotics worldwide, this Handbook remains the essential resource on all aspects of this complex subject.

New features include:

- Information on emerging trends in artificial intelligence, micro-and nano-robots, CAD/graphic simulators, environmental protection, and more

- Coverage of robotic applications to a wide range of manufacturing and service industries

- Updated material on the automotive, electronics, and aerospace industries

- Companion CD-ROM with hands-on demonstrations and programs

January 1999 0-471-17783-0 \$150.00 US / \$210.50 CAN 1,184 pp. Cloth

\section{(2) WILEY}

Available through your vendor

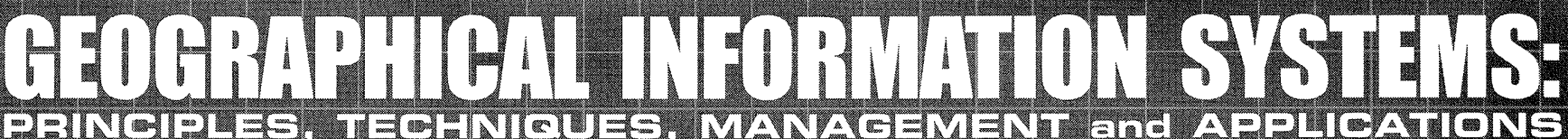

\section{The New Revised and Expanded Flagship Publication}

\section{The definitive Geographical Information Systems (GIS) sourcebook with total access to the most up-to-date research and trends in geographical information systems.}

The new expanded GEOGRAPHICAL INFORMATION SYSTEMS: Principles, Techniques, Management and Applications is the essential reference tool for everyone interested in GIS (GIS educators in universities, colleges and schools, developers of GIS software and data: researchers in geographical information science, geomatics, geography, surveying and cartography; students and professional GIS users in government, industry and commerce), giving a thorough detailed view of GIS for all those who seek the fund of knowledge provided by this invaluable fully cross-referenced two volume set.

\section{GEOGRAPHICAL INFORMATION SYSTEMS: Principles, Techniques,}

Management and Applications provides:

- Comprehensive definitive reference work presenting the major application areas, introducing the relevant techniques and discussing the most important principles of GIS

- Describes best practice key approaches to implementing and managing a GIS

- Interfaces central principles and organizing concepts with professional practice - through extensive cross referencing and the use of real case studies

- Two volume cased set, fully cross-referenced, lavishly illustrated in full color and black and white

\section{Edited by Paul A. Longley, Michael F. GoOdchild,} David J. Maguire AND David W. RHIND

Approximately 80 chapters and over 100 contributors pool the experience of researchers, lecturers and professionals well respected in their chosen disciplines within GIS, from all across the world, to give a fund of knowledge for users at all levels.

GEOGRAPHICAL INFORMATION SYSTEMS: Principles, Techniques,

Management and Applications contains the definitive research work:

- an abstract with every chapter

- consolidated and individual bibliographies

- extensive cross-referencing between theory and application issues - comprehensive index

\section{About the Editors:}

PAUL A. LONGLEY is Professor of Geography at the University of Bristol, in the U.K. MICHAEL F. GOODCHILD is Professor of Geography at the University of California, DAVID J. MAGUIRE is the Director of Product Planning at Environmental Systems Research Institute in Redlands, California and DAVID W. RHIND is the Director General of Ordnance Survey of Britain.

0-471-32182-6 $\cdot 2$-volume cased set $\cdot 1,300$ pages, Cloth (C) 1998

Special Pre-publication price of $\mathbf{\$ 2 9 5 . 0 0}$ until $\mathbf{4 / 3 0 / 9 9}$, $\$ \mathbf{3 4 5 . 0 0}$ thereafter

Available through your vendor

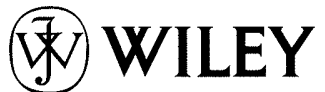

